\title{
Multi-wavelength imaging observations of plasma depletions over Kavalur, India
}

\author{
H. S. S. Sinha ${ }^{1}$, P. K. Rajesh ${ }^{1}$, R. N. Misra ${ }^{1}$, and N. Dutt ${ }^{1}$ \\ ${ }^{1}$ Physical Research Laboratory, Navrangpura, Ahmedabad 380 009, India
}

Received: 17 January 2001 - Revised: 18 June 2001 - Accepted: 18 July 2001

\begin{abstract}
Observations of ionospheric plasma depletions were made over Kavalur $\left(12.56^{\circ} \mathrm{N}, 78.8^{\circ} \mathrm{E}\right.$, Mag. Lat $4.6^{\circ} \mathrm{N}$ ), India during March-April 1998 using an all sky optical imaging system operating at $630 \mathrm{~nm}, 777.4 \mathrm{~nm}$ and $557.7 \mathrm{~nm}$. Out of 14 nights of observations, plasma depletions were seen only on 9 nights. Except for 21 March 1998, which was a magnetically disturbed period, all other nights belonged to a magnetically quiet period. Some of the important results obtained from these observations are: (a) After the onset of the equatorial spread F (ESF), plasma depletions take typically about $2 \mathrm{hrs} 40 \mathrm{~min}$ to come to a fully developed state, (b) There are three distinct types of plasma depletions: type 1 have an east-west (e-w) extent of $250-350 \mathrm{~km}$ with an inter-depletion distance (IDD) of 125$300 \mathrm{~km}$; Type 2 have an e-w extent of 100-150 km and IDD of 50-150 km; Type 3 have smallest the e-w extent (40$100 \mathrm{~km}$ ) and IDD of 20-60 km, (c) Most of the observed plasma depletions $(>82 \%)$ had their eastward velocity in the range of $25-125 \mathrm{~ms}^{-1}$. Almost stationary plasma depletions $\left(0-25 \mathrm{~ms}^{-1}\right)$ were observed on one night, which was magnetically disturbed. These very slow moving depletions appear to be the result of a modification of the F-region dynamo field due to direct penetration of the electric field and/or changes in the neutral winds induced by the magnetic disturbance, (d) On the night of 21/22 March 1998, which was a magnetically disturbed period, plasma depletions could be seen simultaneously in all three observing wavelengths, i.e. in $630 \mathrm{~nm}, 777.4 \mathrm{~nm}$ and $557.7 \mathrm{~nm}$. It is believed that this simultaneous occurrence was due to neutral density modifications as a result of enhanced magnetic activity. (e) Well developed brightness patterns were observed for the first time in $777.4 \mathrm{~nm}$ images. Earlier, such brightness patterns were observed only in $630 \mathrm{~nm}$ and $557.7 \mathrm{~nm}$ images. These brightness patterns initially appear as very small regions in the northern part of the image and then in about 90 min time, they attain their peak brightness and encompass the entire field-of-view in about $2 \mathrm{hrs} 30 \mathrm{~min}$. In some cases, brightness
\end{abstract}

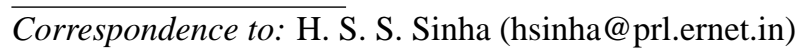

patterns contain one or two well developed plasma depletions within them. (f) The brightness patterns reported here differ from the earlier observations in that they do not show any differential behaviour in the direction of movement before and after the midnight, and that they are present for extended periods of time as large as $6 \mathrm{hrs}$.

Key words. Atmospheric composition and structure (airglow and aurora); Ionosphere (equatorial ionosphere; ionospheric irregularities)

\section{Introduction}

Plasma depletions are large-scale structures of plasma density associated with the phenomenon of the equatorial spread F. Ionospheric plasma depletions, first observed by Hanson and Sanatani (1973) using a satellite-borne experiment, have been observed subsequently by a number of in situ (Kelley et al., 1976; McClure et al., 1977; Benson and Briton, 1983; Jahn et al., 1997; Singh et al., 1997a) and groundbased (Weber et al., 1978; Mendillo and Baumgardner, 1982; Rohrbaugh et al., 1989; Sinha et al. 1991; Mukherjee et al., 1993; Sahai et al., 1994; Sinha, et al., 1996; Mendillo et al., 1997a, b; Taylor et al., 1997; Tinsley et al., 1997; Bittencourt et al., 1997; Fagundes et al., 1997, 1999; Sinha and Raizada, 2000) techniques.

Plasma depletions are produced in the equatorial F-region, move vertically upwards, diffuse along the magnetic field lines and reach lower altitudes at low-latitudes. Sometimes these depletions reach altitudes as high as $2500 \mathrm{~km}$ (Fagundes et al., 1997; Woodman and LaHoz, 1976). It has been generally accepted that plasma depletions are generated in the bottom side of the F-region through the Generalized Rayleigh-Taylor instability mechanism. Various theoretical and experimental studies have identified gravity waves as the seed for the R-T instability to produce irregularities (Kelley et al., 1981, 1986; Huang and Kelley 1996; Singh et al., 1997a; Sinha and Raizada, 2000). Sinha and Raizada (2000) 


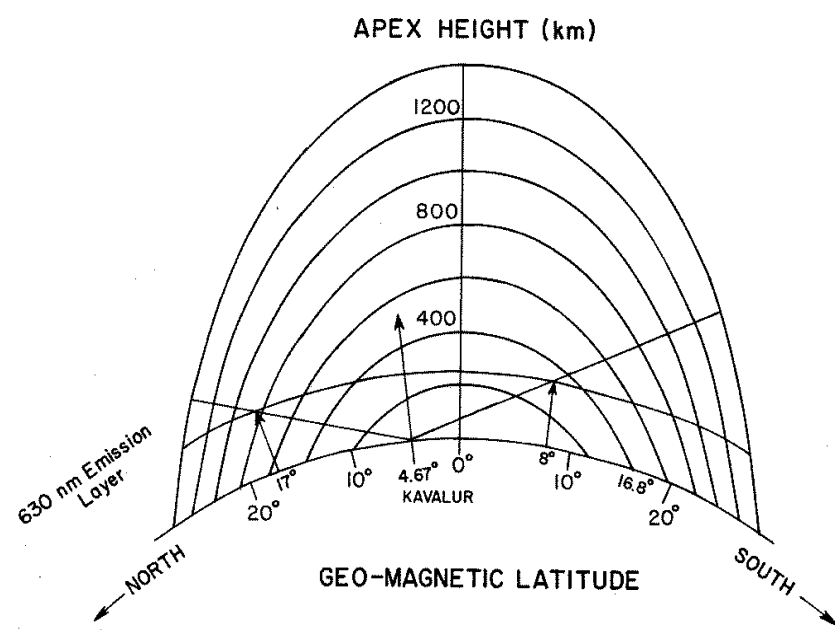

Fig. 1. Viewing geometry of the imager at Kavalur $\left(12.56^{\circ} \mathrm{N}\right.$, $78.8^{\circ} \mathrm{E}$, Mag. Lat $\left.4.6^{\circ} \mathrm{N}\right)$. A field-of-view of $\pm 75^{\circ}$ covers the $630 \mathrm{~nm}$ emission from $17^{\circ} \mathrm{N}$ to $8^{\circ} \mathrm{S}$.

attributed gravity waves of either atmospheric origin or generated in high-latitudes during geomagnetic disturbances, to be the seed for the generation of plasma depletions observed over SHAR. Understanding the mechanism of the generation of plasma depletions can be improved if one knows the properties of plasma depletions and the corresponding geophysical conditions at the time of formation, as well as during the growth phase. The location of Kavalur was selected so that it could be possible to observe the irregularities from their formative stage up to the generation of well developed depletion bands. The optical imaging campaign conducted from Kavalur during March-April 1998 has provided a very good data set, which sheds light on several interesting properties of these large-scale ionospheric irregularities.

\section{Experimental details}

An all sky optical imaging system developed at the Physical Research Laboratory (PRL) was used for observing the plasma depletions over Kavalur. The original version of the instrument (Sinha et al., 1996) was modified and used for the present campaign from Kavalur. The major modification was the incorporation of a $552 \times 816 \times 12$ bit CCD camera instead of a $35 \mathrm{~mm}$ film camera. The other change in the instrument was the computer controlled movement of a filter wheel instead of a manual filter deployment. These modifications resulted in the very precise recording of time and duration of exposures. This imaging system can be operated for \pm 5 nights around a new moon night. Three interference filters, with center wavelengths of $630.0 \mathrm{~nm}, 777.4 \mathrm{~nm}$ and $557.7 \mathrm{~nm}$ and a full width at half maximum (FWHM) of $1 \mathrm{~nm}$, were used. As the size of the CCD array was slightly smaller than the size of the image of the sky made by the optical imager, the image has been slightly chopped off at the top and also at the bottom.
Images grabbed by the CCD camera were processed for flat field correction, image intensifier noise, background illuminations and stationary features, as described by Sinha and Raizada (2000). Calculations of plasma depletion parameters were made by using the assumption that $630 \mathrm{~nm}$, $777.4 \mathrm{~nm}$ and $557.7 \mathrm{~nm}$ emissions come from layers which have their centroids located at $250 \mathrm{~km}, 350 \mathrm{~km}$ and $250 \mathrm{~km}$, respectively. For estimations of the east-west extent and interdepletion distance, an east-west line scan of the image was taken for a number of pixels $( \pm 8)$ around an east-west line, passing through the center of the image (local zenith). The speed of the movement of plasma depletions was calculated from such line scans from a number of images taken every $15 \mathrm{~min}$. In addition to plasma depletions, extended regions having a significantly higher brightness, as compared to the background, were also observed in this campaign. In order to study the relative change in the brightness of these regions, a box average of $50 \times 50$ pixels was taken in the middle of these extended regions in each image. The locus of the box center pointed towards the approximate direction in which these bright patches were moving.

\section{Observations}

The all sky optical imaging system was operated from Kavalur $\left(12.56^{\circ} \mathrm{N}, 78.8^{\circ} \mathrm{E}\right.$, Mag. Lat 4.6 $\left.6^{\circ} \mathrm{N}\right)$ during MarchApril 1998. Figure 1 shows the viewing geometry at Kavalur for the $630 \mathrm{~nm}$ emission. Although a $180^{\circ}$ field-of-view (FOV) system was employed, the actual usable FOV was only about $\pm 75^{\circ}$ from the zenith.

As there was no ionosonde available at Kavalur, the movement of the $\mathrm{F}$ layer and the spread $\mathrm{F}$ were monitored by an ionosonde, which was operated every $15 \mathrm{~min}$ at SHAR $\left(14^{\circ} \mathrm{N}, 80^{\circ} \mathrm{E}, 5.5^{\circ} \mathrm{N}\right.$ dip latitude). Out of a total of 14 nights of observations, plasma depletions were observed only on 9 nights. Very strong plasma depletions were observed on 20, 21, 23 and 29 March 1998. A brightness wave was also seen on many of these 9 nights.

The onset time of spread $\mathrm{F}$ on all four nights when very strong plasma depletions were observed was between 19:30 and 19:45 local time (LT). Figure 2 shows ionograms taken at 19:45, 21:15, 21:45, 22:15, 22:30 and 00:00 LT on the night of 20/21 March 1998, when an intense spread F and well developed plasma depletions were observed. On this night, the onset of spread F was at 19:45 LT and it continued throughout the night and could be clearly seen up to 06:00 LT. Spread $F$ activity on the other three nights was also very intense. Figure 3 shows the variation in the height of the base of the $\mathrm{F}_{2}$ region (h'F) computed from ionograms taken on the nights of 20,21, 23 and 29 March 1998. On two nights (21 and 29 March), the onset of spread $\mathrm{F}$ was at a time when the $\mathrm{F}$ layer was moving upwards; on one night (23 March), the onset occurred when the $\mathrm{F}$ layer was coming down and on another night (20 March), the onset started when the F layer was about to reach its peak. 

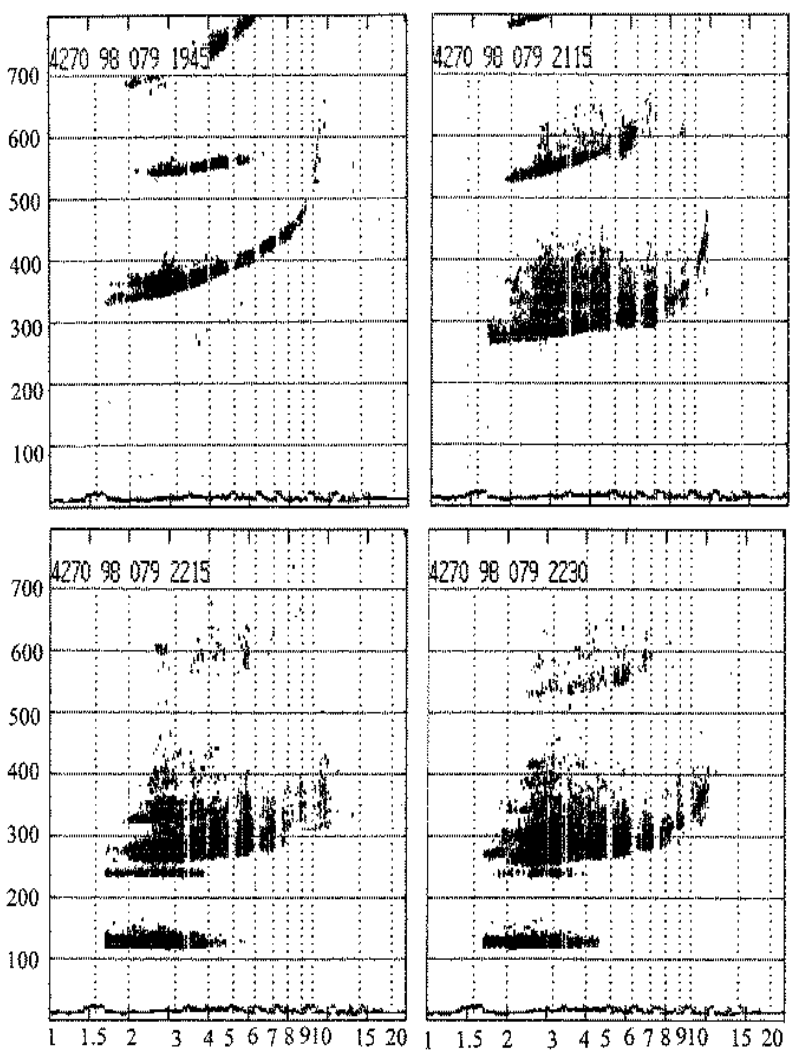
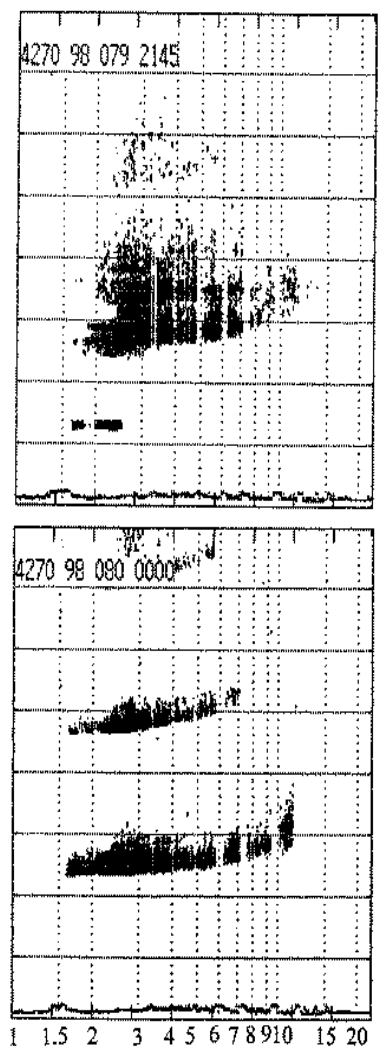

Fig. 2. Ionograms taken at SHAR $\left(14^{\circ} \mathrm{N}, 80^{\circ} \mathrm{E}, 5.5^{\circ} \mathrm{N}\right.$ dip latitude $)$ at $19: 45,21: 15,21: 45,22: 15,22: 30$ and 00:00 LT on the night of 20/21 March 1998.

\section{Results}

Figures $4 \mathrm{a}$ to $\mathrm{c}$ show a series of plasma depletions observed in $630 \mathrm{~nm}, 557.7 \mathrm{~nm}$ and $777.4 \mathrm{~nm}$ on the night of $21 / 22$ March 1998. Out of the four nights when very strong plasma depletions were observed, it was only on this night $(21 / 22$ March 1998) that plasma depletions were observed in all three wavelengths simultaneously. Although the imaging observations started at 19:59:10 LT on the night of 21/22 March 1998 , fully developed plasma depletions could be seen only at 22:34:39 LT, 23:16:48 LT and 21:25:13 LT in $630 \mathrm{~nm}$, $557.7 \mathrm{~nm}$ and $777.4 \mathrm{~nm}$, respectively. Another interesting observation was that the nature of $630 \mathrm{~nm}$ and $557.7 \mathrm{~nm}$ images was quite different up to about midnight, beyond which, there was practically one-to-one correspondence in the $630 \mathrm{~nm}$ and $557.7 \mathrm{~nm}$ images. Absolutely no depletions were seen in $557.7 \mathrm{~nm}$ images before 23:16:48 LT. Development and movement of two band-like structures can be very clearly seen in the $630 \mathrm{~nm}$ and $557.7 \mathrm{~nm}$ images. The intensity of the $777.4 \mathrm{~nm}$ images was relatively weaker. In addition to the depletions in the $630 \mathrm{~nm}$ intensity, Fig. 4 a also shows the appearance of a bright region in the northern part of the image (at 23:19:49 LT), with its sudden intensification (23:33:01 LT), its band-like appearance and ultimate spread in the entire field-of-view up to 01:09:54 LT. Subsequently, the plasma depletions became weak. The time interval between the appearance of the brightness pattern and its growth to the peak intensity was about $93 \mathrm{~min}$. Before attaining its peak intensity, the brightness pattern contains a well marked plasma depletion within it. Similar brightness patterns, but with slightly reduced intensity, were observed in $557.7 \mathrm{~nm}$ as well. But no such brightness patterns were found in $777.4 \mathrm{~nm}$ images on the same night.

Figure 5 shows the $630 \mathrm{~nm}$ images taken during the night of 20/21 March 1998. On this night, observations started at 21:06:12 LT. Signatures of the onset of spread F could be seen even in the very first image, when very weak depletions were observed. Plasma depletions appear to be fully developed at 22:20:17 LT when these could be seen most prominently. Enhancement of the $630 \mathrm{~nm}$ intensity is also seen in these images. At 21:48:29 LT, the brightness pattern appears as a very small region in the northern part of the image. This region subsequently grows in intensity as well as size and beyond 23:19:32 LT, it engulfs the entire field-of-view. This brightness pattern also contains a well marked plasma depletion within it, and takes about $91 \mathrm{~min}$ to grow to its peak value.

Figure 6 shows the $630 \mathrm{~nm}$ images taken during the night of 23/24 March 1998. Appearance of plasma depletions in these images is slightly different. Here, three weak plasma depletions were observed at 22:04:27 LT (not shown in Fig. 6). Initially these depletions were seen in the northern part of the image (at 22:21:14 LT) and they were very close to each other. The separation between these depletions gradually increased. By 00:22:40 LT, the depletions became quite weak and were subsequently not observed. 


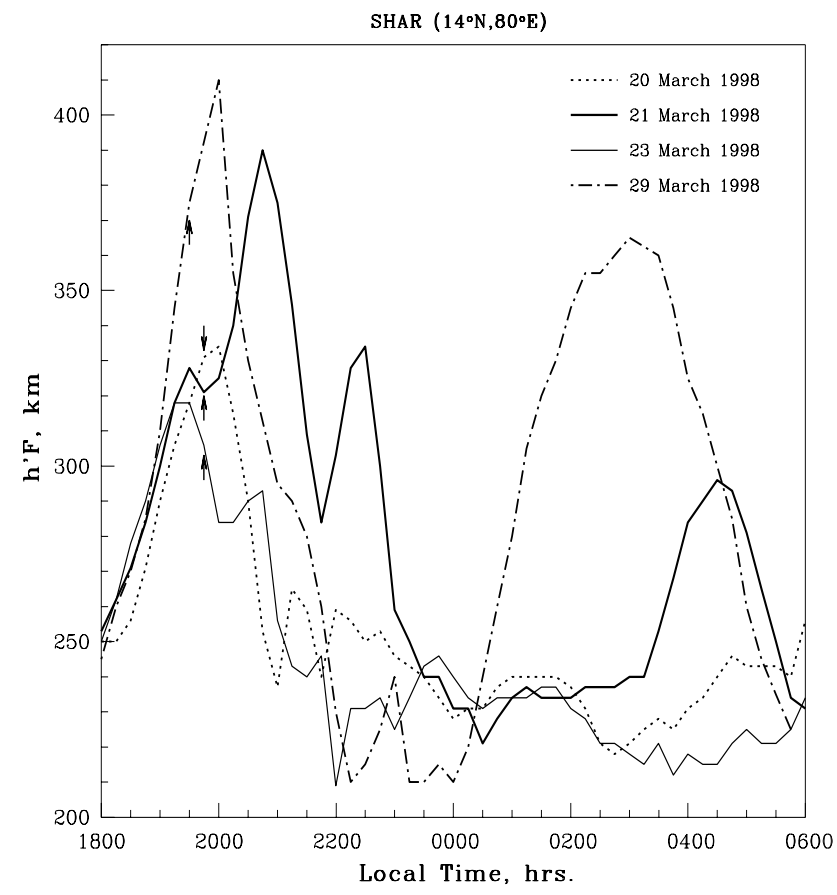

Fig. 3. Variation of h'F over SHAR during the nights of 20, 21, 23 and 29 March 1998. Arrows show the time of onset of spread F.

These images also show the existence of brightness patterns. A small brightness pattern appeared in the northern side at 21:43:09 LT (not shown in Fig. 6), intensified and moved in a southern direction and attained its peak intensity at 23:19:57 LT in about $96 \mathrm{~min}$. This brightness pattern is able to cover the entire field-of-view only at 00:10:36 LT, i.e. it takes 2 hrs 27 min to encompass the entire FOV.

Figure 7 shows the $630 \mathrm{~nm}$ images taken during the night of 29/30 March 1998. The first signatures of plasma depletions were seen in the image taken at 20:04:56 LT (not shown in Fig. 7). In the initial part of the night (up to 22:49:05 LT), three, well separated and very strong plasma depletions could be seen. From 23:04:14 LT onwards, the depletion on the sw sector had weakened, but had taken the form of three very closely spaced bands, which can be seen up to 23:35:13 LT. Afterwards the depletions became too weak. The brightness patterns were seen on this night as well. The brightness was not seen in the image taken at 20:20:11 LT after which there was gap in the data up to 21:17:59 LT. At 21:17:59 LT, the brightness pattern was seen as a small, bright region in the northern part of the image. This brightness pattern attained its peak value at 22:35:03 LT in about 78 min after its first detection. In absence of an image when this brightness pattern was first observed, one can say that it must have taken more than $78 \mathrm{~min}$ to come to its peak brightness.

In order to determine the east-west movement of plasma depletions passing over Kavalur, east-west line scans of each image were taken. An average of 17 such line scans around an east-west line passing through the zenith ware taken. Such an average line scan represents the intensity of an east- west band ( \pm 8 pixels) in the center of the image. Figure 8 shows such an average line scan taken for four $630 \mathrm{~nm}$ images, at approximately $15 \mathrm{~min}$ intervals, on the night of 20 March 1998. One can clearly see the development and eastward movement of one such plasma depletion (shown by an upward arrow) at 22:05:17 LT. A second depletion (shown by downward arrows) also moves eastwards and decays. The eastward velocity of plasma depletions was determined from such line scans.

The top and bottom panels of Fig. 9 show the eastward velocity of two of the most prominent plasma depletions which could be observed for an extended period, calculated from the $630 \mathrm{~nm}$ images on four nights. The direction of movement of plasma depletions was eastwards on all four nights. In general, the eastward drift velocity was maximum during 21:30-22:30 LT and then it decreased to very low values around 01:00 LT, sometimes exhibiting a secondary peak around 00:30 LT. The fastest moving plasma depletions were observed on the night of 29/30 March 1998, when eastward velocities as high as $182 \mathrm{~ms}^{-1}$ were observed. Contrary to this, very slow moving plasma depletions were observed on the night of 21/22 March 1998, when eastward velocities ranged between $0-25 \mathrm{~ms}^{-1}$. It is interesting to note that the night of 21/22 March 1998 was a disturbed night. On the other two nights (20 and 23 March 1998), eastward velocities had intermediate values.

On the night of 28 March 1998, plasma depletions could not be seen continuously due to intermittent cloudiness and hence, no velocity estimates were made for that night. Figure 10 shows the histogram of the different velocities acquired at different times by all 22 depletions seen during an eight night observation period. This shows that there is a lot of variability in the velocity of plasma depletions. At the lower end of velocity $\left(0-25 \mathrm{~ms}^{-1}\right)$, the contribution is primarily from the depletions on the magnetically disturbed night and from a few depletions in the later part of the night. Most of the depletions $(82.5 \%)$ have velocities in the range of 25 $125 \mathrm{~ms}^{-1}$. There were only five occasions when eastward velocities in excess of $125 \mathrm{~ms}^{-1}$ were observed.

In addition to plasma depletions which were observed on four nights, very strong plasma enhancements or brightness patterns were also observed at all three wavelengths on many nights. Figure 11 shows a series of images in $630 \mathrm{~nm}$ recorded on the night of 22/23 March 1998, where a small, bright region was first observed at 19:35:12 LT (not shown in Fig. 11) in the northeast direction, which grew in intensity but did not change much in its size, up to about 21:49:57 LT, after which, the size of the brightness pattern started increasing and it started moving southwards. Beyond 23:04:07 LT, the size of the brightness pattern did not change significantly, but its intensity showed a wavy pattern. Similar brightness patterns were also observed in the $557.7 \mathrm{~nm}$ images on the same night.

We have observed for the first time the presence of brightness patterns in the $777.4 \mathrm{~nm}$ images also. Appearance of brightness patterns in the $777.4 \mathrm{~nm}$ images has not been reported previously. Figure 12 shows the brightness patterns 

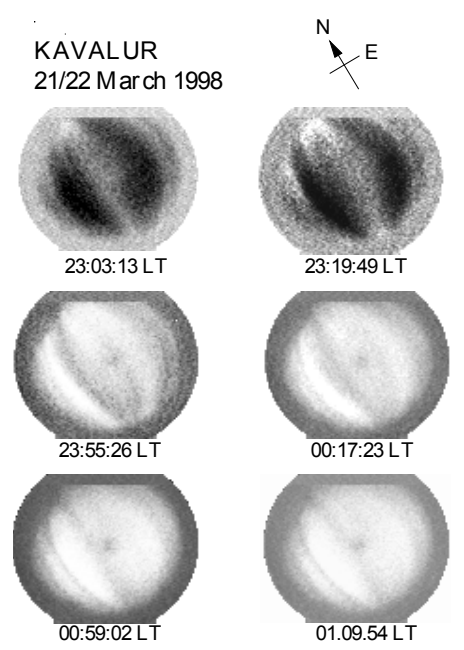

KAVALUR 21/22 March 1998

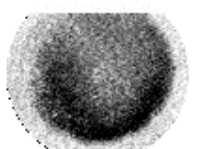

23: 16:48 LT
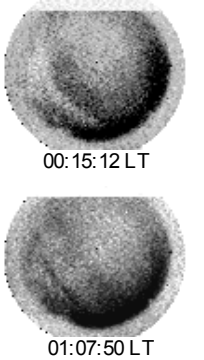
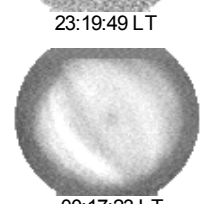

$00: 17: 23 \mathrm{LT}$
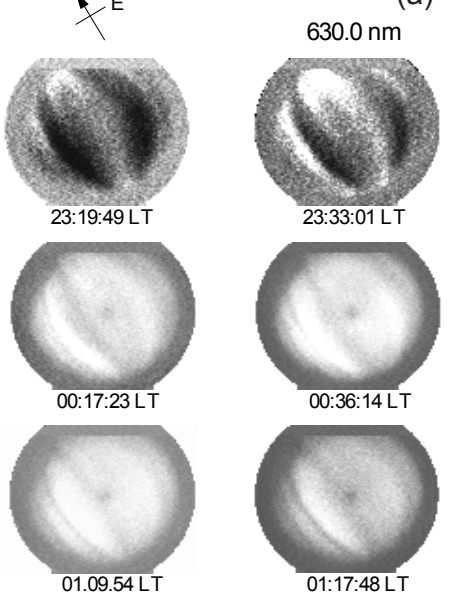

(a)

(c) $557.7 \mathrm{~nm}$

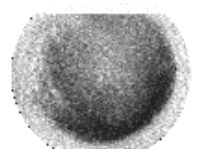

23:30:31 LT

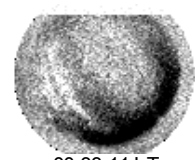

00:33:11 LT
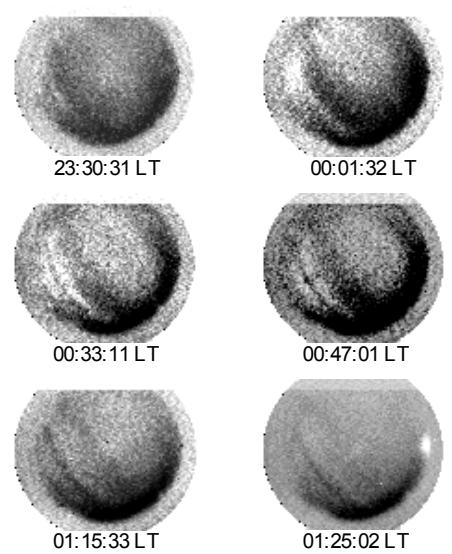

KAVALUR 21/22 March 1998
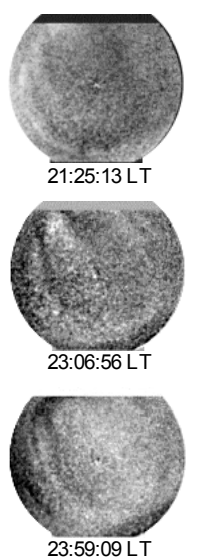

(b)
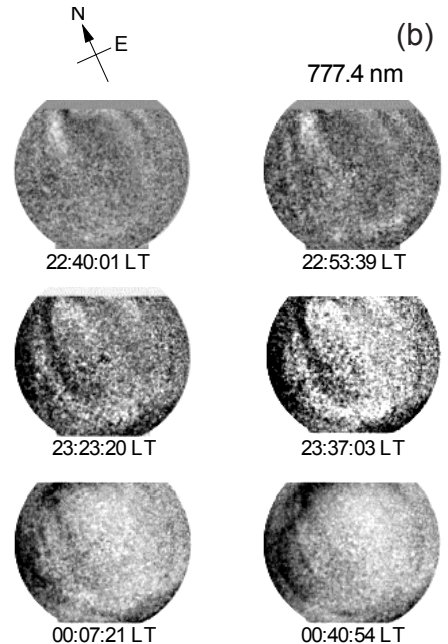

Fig. 4. Plasma depletions as seen in images taken over Kavalur on the night of 21/22 March 1998 (a) at $630 \mathrm{~nm}$, (b) at $557.7 \mathrm{~nm}$ and (c) at $777.4 \mathrm{~nm}$. Times written below images represent local time in hrs, min and s. The arrow points towards the geomagnetic north.

observed in the $777.4 \mathrm{~nm}$ images on the night of 22/23 March 1998. The brightness pattern appears in the FOV in the northern part of the image, as early as 19:53:10 LT, moves towards the equator along the western part of the image and by 23:25:51 LT, it spreads over the entire FOV. Afterwards, it does not show much movement, but by 00:53:52 LT, it is primarily seen only in the eastern half of the image. It is present up to 02:07:28 LT, when observations were stopped.

In order to have an idea of the relative change in the intensities of these brightness patterns, intensity values at all three wavelengths were normalized to 100 arbitrary units. Figure 13 shows relative brightness variations observed in the $557.7 \mathrm{~nm}, 630 \mathrm{~nm}$ and $777.4 \mathrm{~nm}$ images during the night of 22/23 March 1998. The relative brightness of the $630 \mathrm{~nm}$ images is about three times more compared to those in the $557.7 \mathrm{~nm}$ and $777.4 \mathrm{~nm}$ images. The relative brightness in the $630 \mathrm{~nm}$ and $557.7 \mathrm{~nm}$ images show a periodicity which varies between 80 and $90 \mathrm{~min}$. The relative brightness of the $777.4 \mathrm{~nm}$ images, however, do not show any such wavy structures. The brightness in the $630 \mathrm{~nm}$ images shows an increase in intensity by a factor of about 1.5 from 19:30 to

21:30 and beyond 21:30 these patterns show a periodicity ranging between 80 and $90 \mathrm{~min}$. The $777.4 \mathrm{~nm}$ images, however, show an entirely opposite trend. The relative brightness of the $777.4 \mathrm{~nm}$ images is very high at 19:30 and it drops by a factor of 4 by 21:30 and becomes minimum at 23:00, beyond which, it starts increasing.

\section{Discussion}

\subsection{Growth time of plasma depletions}

One of the important features of plasma depletions that is still not clearly understood is the fact that they are observed only on some of the spread F nights (Fagundes et al., 1999; Sahai et al., 2000). In order to understand this aspect, an attempt was made to estimate the typical time for the development of plasma depletions once the ESF has set in. Ionosonde observations from SHAR and imaging observations from Kavalur taken during the present campaign (Fig. 4 to Fig. 7) show that after the onset of ESF, plasma depletions take $2 \mathrm{hrs} 35$ min, 2 hrs 49 min, 2 hrs 49 min and 2 hrs $34 \mathrm{~min}$ to come to 


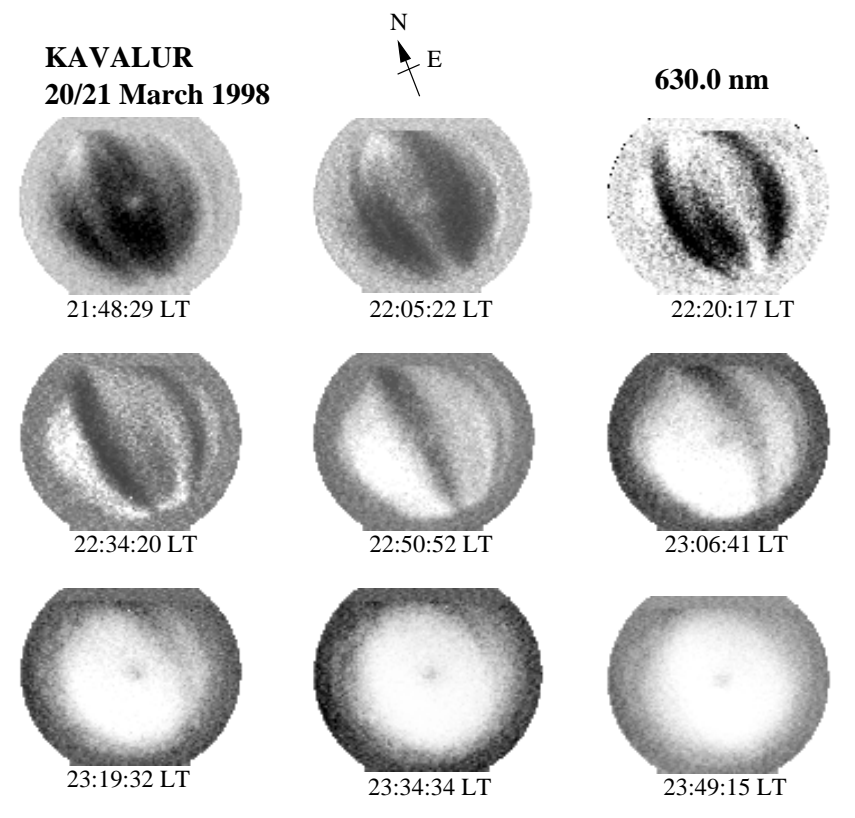

Fig. 5. Plasma depletions in the $630 \mathrm{~nm}$ images taken over Kavalur on the night of 20/21 March 1998. The arrow points towards the geomagnetic north.
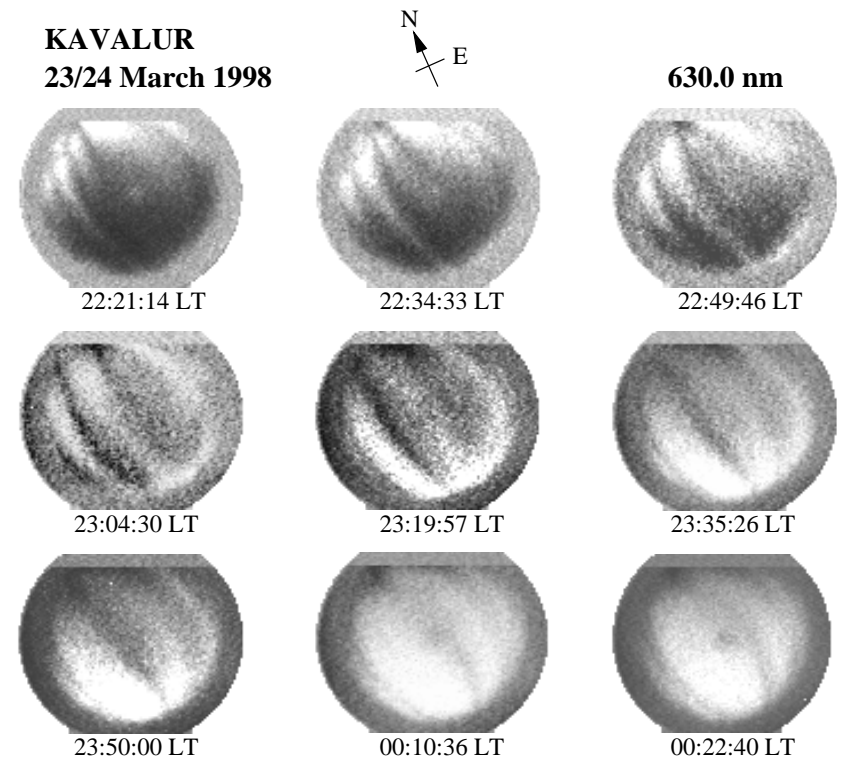

Fig. 6. Plasma depletions in the $630 \mathrm{~nm}$ images taken over Kavalur on the night of 23/24 March 1998. The arrow points towards the geomagnetic north.

the fully developed stage on the nights of 20/21, 21/22, 23/24 and 29/30 March 1998, respectively.

The main mechanism for the generation of largescale structures associated with the spread $\mathrm{F}$ is the Generalised Rayleigh-Taylor Instability (GRTI) mechanism. The growth rate of GRTI depends on many parameters, such as electron density gradient, ion-neutral collision frequency, vertical and zonal winds, electric fields, tilt of ionosphere, etc. It is well-

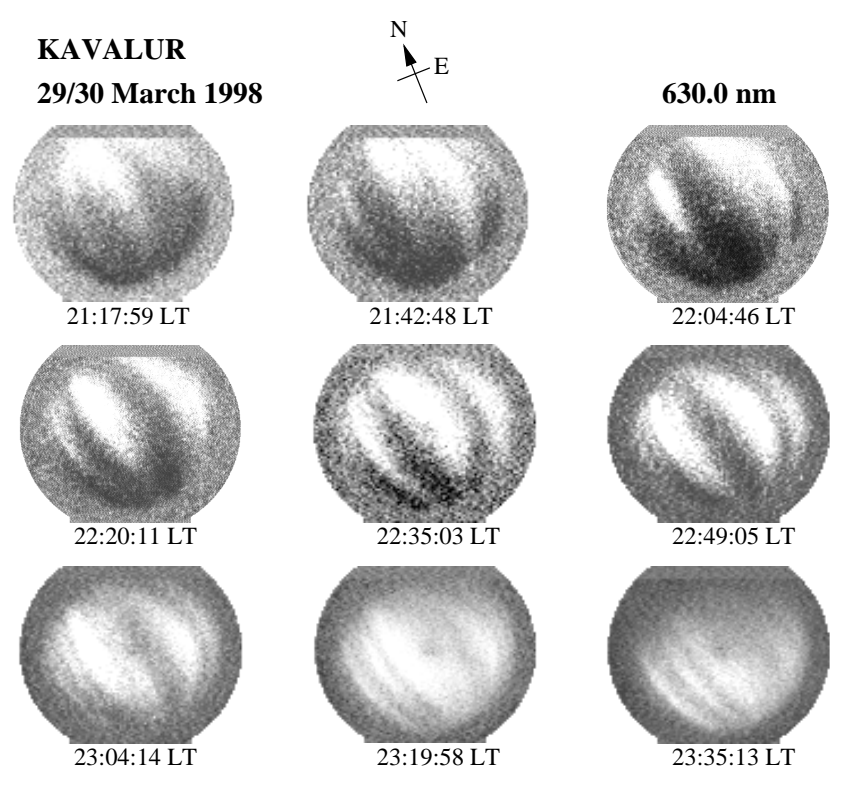

Fig. 7. Plasma depletions in the $630 \mathrm{~nm}$ images taken over Kavalur on the night of 29/30 March 1998. The arrow points towards the geomagnetic north.

Table 1. East-west scale $\left(\lambda_{E-W}\right)$, inter-depletion distance (IDD) and the total number of plasma depletions observed $(\mathrm{N})$ in each category during eight nights of observation.

\begin{tabular}{cccc}
\hline $\begin{array}{c}\text { Type of } \\
\text { Depletion }\end{array}$ & $\begin{array}{c}\lambda_{E-W} \\
\mathrm{~km}\end{array}$ & $\begin{array}{c}\text { (IDD) } \\
\mathrm{km}\end{array}$ & $\mathrm{N}$ \\
\hline Type 1 & $250-350$ & $125-300$ & 10 \\
Type 2 & $100-150$ & $50-150$ & 16 \\
Type 3 & $250-350$ to $40-100$ & $20-60$ & 2 \\
\hline
\end{tabular}

known that the growth rate of GRTI is not sufficient to produce the observed amplitudes starting from thermal fluctuations and it is necessary to have some other mechanism to produce a seed perturbation. Gravity waves are considered to be the main source that produce the necessary initial density perturbation needed for the generation of these irregularities (Kelley et al., 1981). As the growth rate of GRTI depends on a number of parameters, one expects to observe irregularities in different stages of development when these parameters assume different values. The contribution to the growth rate of GRTI instability by the gravitational term is more when the F layer is at higher altitudes, while zonal winds and electric fields are effective at lower altitudes (Tsunoda 1981, Kelley et al., 1981). In addition, during the descending phase of the $F$ layer, the tilt of the ionosphere is such that zonal winds have a stabilising effect.

As shown in Fig. 3, the location of h'F was at different altitudes and the layer was moving either upwards or downwards. Thus, the background ionospheric conditions on all four nights, which we have reported here show a significant variation. But the interesting result is that on all four 


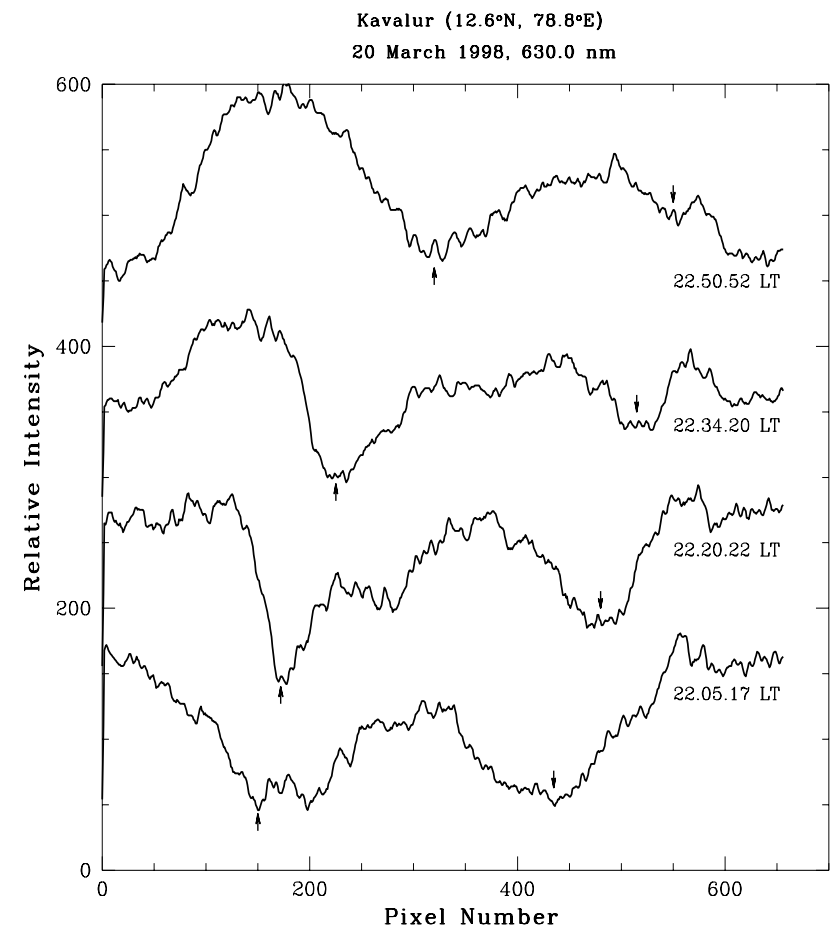

Fig. 8. Variation in the relative intensity of $630 \mathrm{~nm}$ along an eastwest band ( \pm 8 pixels) passing through the center of the image (i.e. the local zenith) in four images taken over Kavalur at approximately 15 min intervals on the night of 20/21 March 1998. Upward and downward arrows show eastward movement of two plasma depletions.

nights, the irregularities take nearly same time ( $2 \mathrm{hrs} 40 \mathrm{~min})$ to come to a fully developed stage from the time that the first signatures of ESF were seen on the ionograms. Thus, our results indicate that even though there are differences in the background ionospheric conditions at the onset time, the average growth time required for the appearance of fully developed depletions is nearly the same in all cases. This also tells us that plasma depletions will be produced if the background conditions are conducive and can provide some minimum growth rate. These background conditions need not be the same on all nights. But if these minimum conditions are not satisfied, depletions in large-scale structures may not develop to the extent wherein they are defined as plasma depletions.

Thus, present observations show that, on an average, plasma depletions take about $2 \mathrm{hrs} 40 \mathrm{~min}$ to come to a fully developed stage after the onset of ESF. Singh et. al. (1997b) found from their satellite-borne ion probe that the small ion perturbations took nearly 3 hrs to develop into a wave structure. Our observations show an excellent agreement with the satellite-borne in situ measurement. Thus, the time required for the growth of fully developed plasma depletions can be taken to be in the range of 160-180 min.

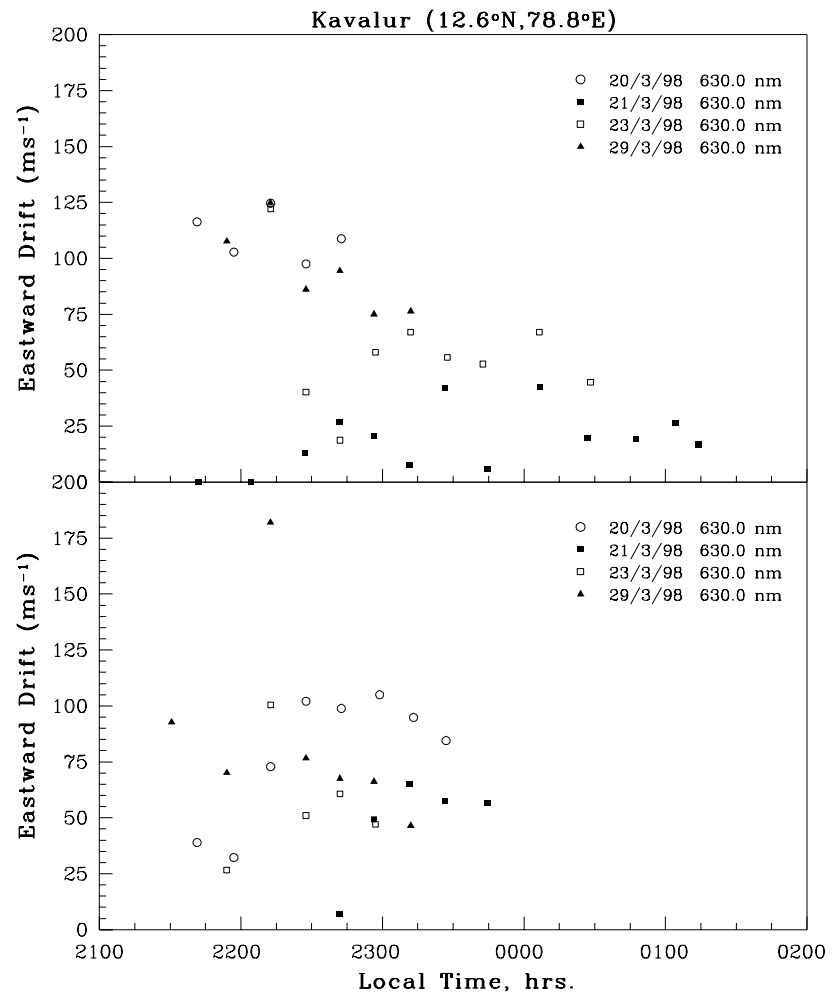

Fig. 9. Eastward drift velocity of plasma depletions over Kavalur during nights of 20/21, 21/22, 23/24 and 29/30 March 1998. Top and bottom panels show velocities of two different depletions observed on the same night.

\subsection{East-west extent and inter-depletion distance}

Our observations of plasma depletions, as shown in Fig. 4 to Fig. 7, show basically three types of plasma depletions. Table 1 shows the number of depletions observed in each class during the present campaign. The first type of depletion has a fairly large east-west extent $(250 \mathrm{~km}$ to $350 \mathrm{~km})$ and normally, one sees two such depletions (Fig. 4 a, b and Fig. 5) most of the time. The eastward velocities of these depletions were such that when one depletion moved out of the eastern horizon, another one started appearing in the west. The typical inter-depletion distance (IDD) for such depletions was in the range of $125-300 \mathrm{~km}$. The second category of plasma depletion is the one wherein about three plasma depletions, each having a relatively small east-west extent $(100-150 \mathrm{~km})$ were observed initially and all of these moved nearly with the same velocity, at least up to 00:00 LT, beyond which, their velocities showed differential behaviour. The range of IDD for such depletions was $50-150 \mathrm{~km}$. The third type of plasma depletion initially had a large east-west extent $(250 \mathrm{~km}$ to $350 \mathrm{~km})$, but after about 23:00 LT, three to four depletions, each having very a small east-west extent (40$100 \mathrm{~km}$ ), bunched together and moved very slowly (Fig. 7). The range of IDD for such depletions was $20-60 \mathrm{~km}$.

Inter-depletion distances give information about the wavelength of the initial seed perturbation, which grows and ulti- 


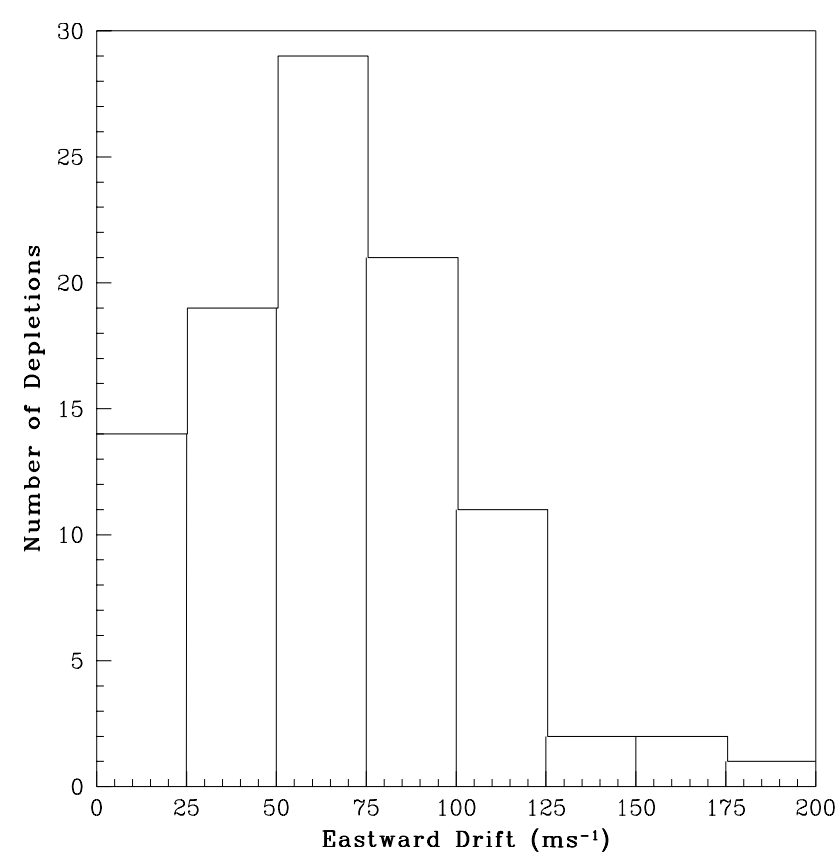

Fig. 10. Histogram of the number of depletions observed in different velocity ranges during all eight nights of observation.

mately results in the generation of electron density irregularities. So the observed inter-depletion distances should be representative of the scale sizes of the gravity waves responsible for the initial perturbation. There are basically three types of gravity waves, which can produce large-scale plasma irregularities in the F-region. The first ones, which are the most well-known type, are the gravity waves present in the Fregion. It was shown by Hines (1974) that at $225 \mathrm{~km}$ altitude, gravity waves have a lower wavelength cutoff of $100 \mathrm{~km}$. Thus, F-region gravity waves are basically large-scale gravity waves. The second type of gravity waves is present in the E-region and they produce the electric field perturbations, which can be transported along the geomagnetic field lines to the F-region (Prakash, 1999). These gravity waves from the E-region could have scale sizes down to about $15-20 \mathrm{~km}$ (Prakash, 1999). The third type of gravity waves comes from the auroral regions during a magnetic disturbance (Kelley et al. 1981); such gravity waves have scale sizes in excess of $1000 \mathrm{~km}$.

In view of the above, we feel that the Type 1 depletions, which have wavelengths in the range of $250-350 \mathrm{~km}$, are produced by the gravity waves in the F-region. The depletions that we classified as Type 2 and Type 3 have very small values of inter-depletion distance $(<150 \mathrm{~km})$. We believe that these depletions are produced due to the E-region gravity waves through the mechanism suggested by Prakash (1999). As we have observed the simultaneous existence of all three type of depletion, our results point to the simultaneous involvement of many types of gravity waves, in addition to the GRTI, in the production of the observed plasma depletions. The east-west extent and the inter-depletion distances ob- served by us are in agreement with those observed by Singh et al. (1997b). 5.3 Simultaneous occurrence in the 630, 777.4 and
$557.7 \mathrm{~nm}$ images

An interesting observation is that only on the night of 21/22 March 1998, were plasma depletions present simultaneously in all three wavelengths. On this particular night, the first signatures of plasma depletions were seen at 21:25:13 LT in the $777.4 \mathrm{~nm}$ images; the depletions were next seen in the $630 \mathrm{~nm}$ images at 22:34:39 LT and finally in the $557.7 \mathrm{~nm}$ at 23:16:38 LT. An attempt was made to find out what special features were associated with this night, which gave rise to simultaneous observations of plasma depletions in $630 \mathrm{~nm}$, $777.4 \mathrm{~nm}$ and $557.7 \mathrm{~nm}$. The onset of spread $\mathrm{F}$ on this night was at 19:45 LT, when the base of the F layer was located around $320 \mathrm{~km}$.

The $557.7 \mathrm{~nm}$ signal is made up of two parts, one coming from the F-region and the other coming from the mesosphere. The F-region OI $557.7 \mathrm{~nm}$ emission is through the dissociative recombination of $\mathrm{O}_{2}^{+}$or $\mathrm{NO}^{+}$molecules, which are produced through charge exchange or ion atom exchange reactions between $\mathrm{O}^{+}$and neutrals. The mesospheric emission of OI $557.7 \mathrm{~nm}$ is given by the Barth mechanism. Normally, the contribution of mesospheric component is dominant as compared to that of the F-region. A modification of the neutral and plasma density distribution, which follows a magnetic disturbances event, can thus result in a significant increase in the F-region's contribution to the $557.7 \mathrm{~nm}$ signal.

Simultaneous observations of plasma depletions in $630 \mathrm{~nm}$ and $557.7 \mathrm{~nm}$ were conducted earlier by Mendillo et al. (1997a), who found that very similar structures were present in both the 630 and $557.7 \mathrm{~nm}$ images. The present observations, on the other hand, show that up to about midnight, although the $630 \mathrm{~nm}$ images show the presence of plasma depletions, no such structures are seen in the $557.7 \mathrm{~nm}$ images. Beyond midnight, both images show more or less similar structures. We feel this was the case because on this particular night, there was a strong magnetic disturbance during which heating of low-latitudes and the subsequent modification of the neutral density took place through a largescale circulation. In the presence of such density changes, an enhanced contribution of a $557.7 \mathrm{~nm}$ emission from the F-region is possible.

Although very weak signatures of depletion in $777.4 \mathrm{~nm}$ were present as early as 21:25:13 LT, the depletions became very prominent after 23:23:20 LT. As the time interval between the onset of the magnetic disturbance and the observation of prominent depletions was around $6 \mathrm{hrs}$, the occurrence of prominent depletions in the $777.4 \mathrm{~nm}$ images could be due to the enhancement of atomic oxygen subsequent to the magnetic disturbance, as suggested by Prolss (1982, 1995). 


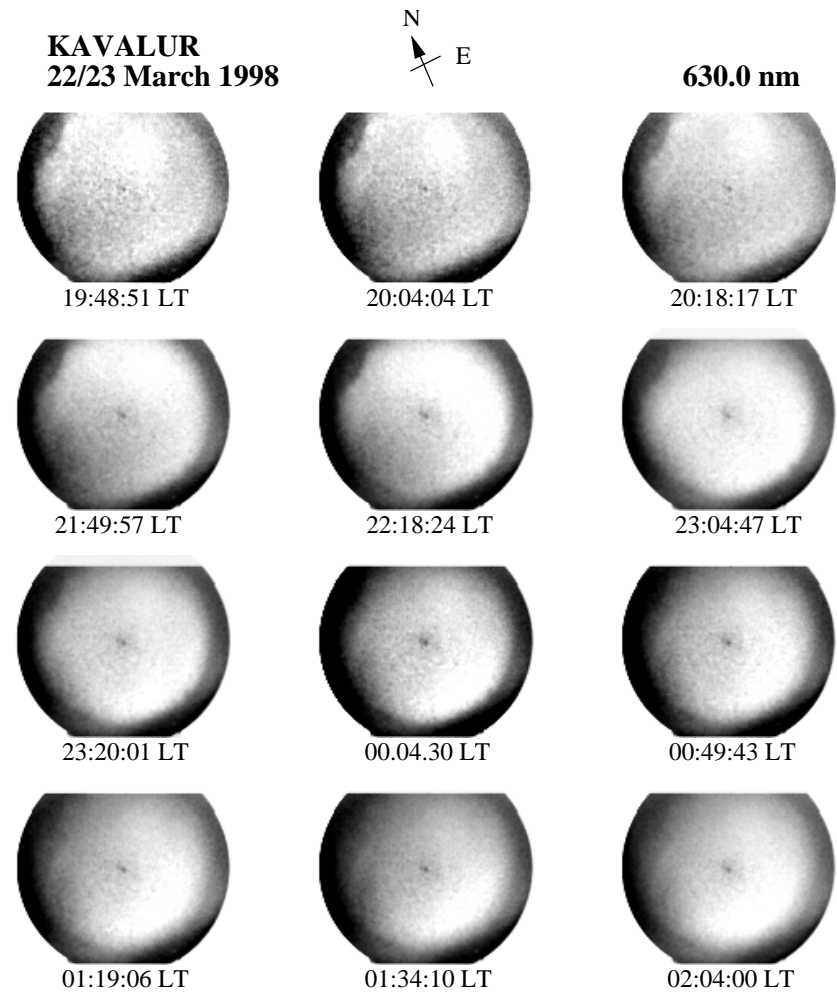

Fig. 11. Plasma enhancements or brightness patterns in the $630 \mathrm{~nm}$ images taken over Kavalur on the night of 22/23 March 1998. The arrow points towards the geomagnetic north.

\subsection{Eastward velocity}

Except for a single plasma depletion which had an eastward velocity of $182 \mathrm{~ms}^{-1}$, most of the plasma depletions observed in the present campaign had their eastward velocities in the range of $25-125 \mathrm{~ms}^{-1}$. These observations are commensurate with the normal behaviour of the F-region dynamo and are in agreement with values reported earlier (Mendillo et al., 1997a; Fejer, 1991; Sinha and Raizada, 2000). Some of the plasma depletions had very small to practically zero eastward drift velocity. Plasma depletions observed on the night of 21/22 March 1998 belong to this class. These plasma depletions had their eastward drift velocities in the range of 0 $25 \mathrm{~ms}^{-1}$. Very slowly moving depletions, as observed by us during a magnetically disturbed period, have been observed earlier only once by Fagundes et al. (1999) during a magnetically quiet and weak spread F period. Fagundes et al. (1999) observed north-south aligned bands, which practically did not move for about an hour.

Our observations of very slow depletions were made on a magnetically disturbed night. On this night, these depletions started appearing around 21:34:29 LT. We feel that these sluggish depletions could be due to a severe modification of the F-region dynamo electric fields. The modification of the F-region dynamo can be due to the modification of the Fregion neutral winds or due to the direct penetration of magnetospheric electric fields to the equatorial ionosphere (Gon-

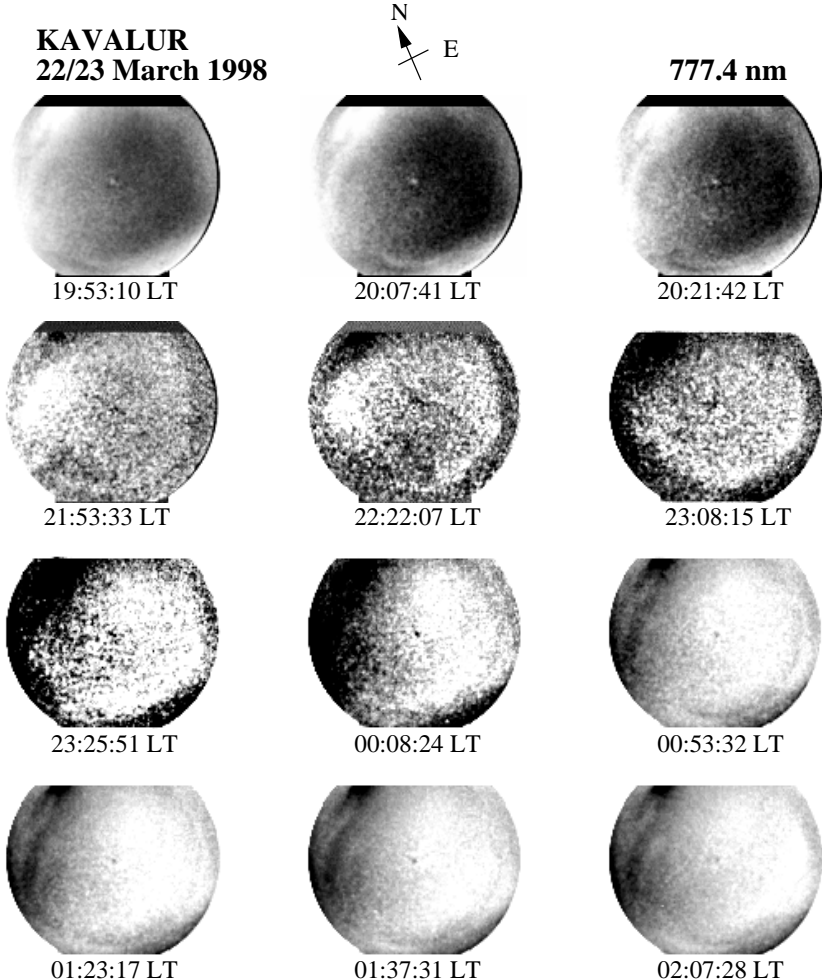

Fig. 12. Plasma enhancements or brightness patterns in the $777.4 \mathrm{~nm}$ images taken over Kavalur on the night of 22/23 March 1998. The arrow points towards the geomagnetic north.

zales et al., 1979). The time of the first appearance of these sluggish depletions (21:34:29 LT) is commensurate with time scales of the direct electric field penetration mechanism. The appearance of depletions in the later part of the night can be explained in terms of a dynamo field modification due to the direct penetration of electric fields and/or planetary wave circulation. Details of these effects during a magnetic disturbance are discussed in the next section.

\subsection{Effect of magnetic disturbance}

Out of the four nights of observations which we have described here, 21 March 1998 was a magnetically disturbed night, with $K_{p}$ values reaching as high as $6^{-}$and $6^{+}$during the periods 12:00-15:00 UT and 15:00-18:00 UT, respectively. Interestingly, it was only on this night that we observed plasma depletions which showed very small $(0$ $25 \mathrm{~ms}^{-1}$ ) eastward drift. In addition, on this night, we could observe plasma depletion structures in all three wavelengths $(630 \mathrm{~nm}, 557.7 \mathrm{~nm}$ and $777.4 \mathrm{~nm})$. In the following paragraphs, an attempt is made to examine the possible influence of this high-latitude disturbance on the features observed at a low altitude station.

The coupling of high-latitude and low-latitude atmospheres can be either through the changes in the neutral atmosphere caused by the heating and subsequent changes in the neutral wind pattern or through electrical field penetrations 


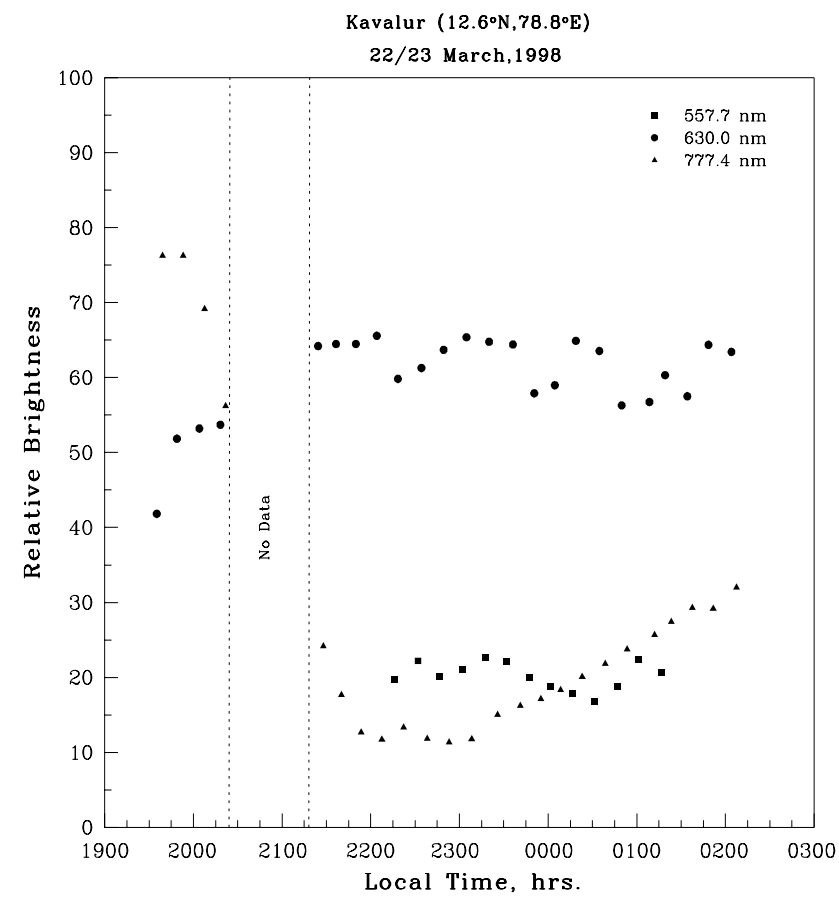

Fig. 13. Variation in the relative brightness of the airglow enhancements in an area of $50 \times 50$ pixels approximately located at the center of the brightness pattern on the night of 22/23 March 1998.

which can change the plasma dynamics at low-latitudes and affect neutral winds through momentum transfer (ion drag). Sahai et al. (1998) have shown that whenever $K_{p}$ index assumes a value greater than 5 , the drift of magnetic disturbance to equatorial latitudes can result due to prompt penetration of high-latitude electric fields to lower latitudes. If the changes are due to electrical coupling, low-latitudes follow the high-latitude disturbances almost instantaneously (Gonzales et al., 1979). If the observed effects of high-latitude magnetic disturbances appear at low latitudes after a time period of 4-6 hrs, it can be thought of as a result of the induced effect of the high-latitude activity on equatorial neutral atmosphere either through large-scale circulation or through travelling atmospheric disturbances.

Plasma depletions, once generated, usually drift eastwards with ambient plasma. The eastward velocity depends on the F-region dynamo, which is controlled essentially by neutral zonal winds and electric fields. Therefore, any change in the drift velocity of plasma depletions can be thought of as a result of the corresponding change in the neutral wind velocity or ionospheric electric fields, thereby affecting the F-region dynamo. Since 21 March 1998 was the only disturbed night during the present observation period, it can be concluded that the sluggish plasma depletions observed on that night could be due to the effect of the enhanced geomagnetic activity.

The time of occurrence of high $K_{p}$ values shows that the change in the F-region dynamo could be either due to a change in the neutral wind pattern or due to the penetra- tion of disturbance electric fields to low-latitudes. There are primarily three mechanisms which can cause heating in the low-latitudes and a change in the wind pattern and hence, a change in the F-region dynamo electric fields (Prolss, 1982). They are (1) ring current neutral particle injection, (2) largescale circulation and (3) travelling atmospheric disturbances. The F-region dynamo can also be altered almost instantaneously by direct penetration of magnetospheric and plasmaspheric electric fields. The time scales involved in the ring current neutral particle injection and large-scale circulation does not match with the first appearance of ( 21:34:29 LT) slow drifting bubbles reported here. If the travelling atmospheric disturbances would have been responsible, then we expect to observe signatures of large-scale gravity waves in our all sky images, as seen by Sinha and Raizada (2000). But such signatures were absent in the images of 21 March 1998. Therefore, one can conclude that the observed changes in plasma depletion drifts at the time of first appearance (21:34:29 LT) on 21 March 1998 might be due to the direct penetration of the disturbance electric fields from the highlatitudes to low-latitudes, affecting the F-region dynamo. Based on the time scales involved, plasma depletions observed in the later part of this night (after 23:00 LT) can be due to dynamo field modifications either through the direct electric field penetration and/or the planetary wave circulation.

The fact that plasma depletions were seen in the $557.7 \mathrm{~nm}$ and $777.4 \mathrm{~nm}$ images taken on the night of 21 March 1998 points to the fact that there had been a modification of neutral densities also on this night. The appearance of plasma depletion structures in the $557.7 \mathrm{~nm}$ images starts only around 23:10:48 LT, but the $630 \mathrm{~nm}$ emissions show clear plasma depletions beforehand. The otherwise faint $777.4 \mathrm{~nm}$ emission showed very clear plasma depletions from about 23:23:20 LT. This corresponds to a time gap of nearly 6 hrs after the commencement of high-latitude disturbances (assuming 12:00 UT to be the starting time).

Prolss $(1982,1995)$ has shown that the geomagnetic disturbances can cause density enhancements of all types of neutral particles at low-latitudes, while at higher latitudes, heavier elements (Ar, $\mathrm{N}_{2}$ etc.) show enhancement, and lighter elements $(\mathrm{O}, \mathrm{He}$ etc.) show a depletion in density at $\mathrm{F}$ layer altitudes. This can result in a reduction of electron density in the F layer at mid- and high-latitudes (negative ionospheric storm). The enhancement of the atomic oxygen density at $\mathrm{F}$ layer heights in the equatorial and low-latitudes can affect the F-region airglow chemistry and result in enhanced emission at $777.4 \mathrm{~nm}$ and $557.7 \mathrm{~nm}$. Therefore, it can be concluded that the observed enhancements in the $557.7 \mathrm{~nm}$ and $777.4 \mathrm{~nm}$ emissions were due to the increase in low-latitude neutral densities as a result of the magnetic disturbance.

\subsection{Plasma enhancement / brightness patterns}

The brightness patterns reported here include some new results. We have observed for the first time the presence of brightness patterns in the $777.4 \mathrm{~nm}$ images. Our observations 
indicate that these brightness patterns start with a very small spatial extent in the northern part of the image and typically take about 90 min to grow to their peak amplitudes. During their intensification, these bright regions grow in size and most of the time cover the entire field-of-view. Sometimes, these brightness patterns contain one or more well developed plasma depletions within them. The general trend observed in our images is that these brightness patterns start appearing in the northern part of the FOV and slowly move towards the southern part of the image, i.e. towards the equator. In most cases they reach the southern part by local midnight. After midnight, the brightness patterns grow in size, at times covering the entire field-of-view (Fig. 11), and hence, show practically no movement.

Colerico et al. (1996) has reported the appearance and dynamics of brightness waves (BW) in the all sky images during MISETA campaign and concluded that they are the optical signatures of midnight temperature maximum (MTM). Mendillo et al. (1997a) have also reported the appearance of BWs in their all sky images and attributed this phenomenon to MTM. It is interesting to note that BWs reported by Mendillo et al. (1997a) were very short-lived and were termed as transients. Sinha and Raizada (2000) reported the existence of brightness by a factor as high as 3.8, which existed for a much longer time ( $\sim$ few tens of min). The present understanding of this phenomenon is that the observed brightness in the $630 \mathrm{~nm}$ and $557.7 \mathrm{~nm}$ images is due to the enhancement in the airglow emission caused by the downward movement (midnight collapse) of the $\mathrm{F}$ layer, which is due to the reversal of meridional neutral winds from equatorwards to polewards as a result of the pressure bulge, which accompanies the MTM (Colerico et. al, 1996). There are pre-midnight as well as midnight BW events. The equatorward or poleward movement of the BWs depends on the (eastward or westward) tilt of the MTM and the movement of the instrument location through the MTM at the corotation speed of the Earth. The absence of BWs are not expected in the $777.4 \mathrm{~nm}$ images due to the fact that the $777.4 \mathrm{~nm}$ emission does not depend on h'F variations.

There are two main differences in brightness patterns seen in our images. Colerico et al. (1996) have classified the BW events as pre-midnight brightness waves (PMBWs) and midnight brightness waves (MBWs), depending on their time of occurrence. The PMBWs occur during 20:00-22:00 LT, while MBWs are observed during 00:00-02:00 LT. In some cases, both PMBWs and MBWs are observed on the same night. The direction of movement of PMBWs is equatorward, whereas the MBWs move poleward. The brightness patterns observed by us do not show any such difference in their direction of motion during different parts of the night. As shown in Fig. 11, brightness patterns observed by us are continuously present from 19:48:51 LT to 02:04:00 LT. The second difference is the appearance of brightness patterns in the $777.4 \mathrm{~nm}$ images (Fig. 12). This is a new observation and prompts us to investigate more the origin of these brightness patterns, as their appearance in about $777.4 \mathrm{~nm}$ in not expected if the generation of BWs is due to the phenomenon of the MTM.

Figure 13 shows the variation in the relative brightness of these brightness patterns with time for all three wavelengths obtained on 22/23 March 1998. In the initial part of the night, i.e. up to $21: 30 \mathrm{hrs}, 630 \mathrm{~nm}$ images showed a brightness enhancement by a factor of 1.5 with time and in the same duration the $777.4 \mathrm{~nm}$ images showed a decrease in brightness by a factor of 4 . Beyond 21:30 hrs, the $630 \mathrm{~nm}$ and $557.7 \mathrm{~nm}$ images show a wave-like behaviour with a periodicity of 80-90 min, whereas the $777.4 \mathrm{~nm}$ images do not show any wavelike pattern. These features appear to be a new type and need to be explained.

\section{Summary}

This paper reports some new observations of ionospheric plasma depletions taken using an all sky optical imaging system developed at PRL. It is found that plasma depletions take $2 \mathrm{hrs} 40 \mathrm{~min}$ to $3 \mathrm{hrs}$ to come to a fully developed state. There were three distinct classes of plasma depletions with eastwest extents of $250-350 \mathrm{~km}, 100-150 \mathrm{~km}$ and $40-100 \mathrm{~km}$ and corresponding inter-depletion distances of $125-300 \mathrm{~km}$, $50-150 \mathrm{~km}$ and $20-60 \mathrm{~km}$, respectively.

Out of the 14 nights of observation, the simultaneous occurrence of plasma depletions in the images of $557.7 \mathrm{~nm}$, $630 \mathrm{~nm}$ and $777.4 \mathrm{~nm}$ was observed only on 21/22 March 1998. This particular night was characterized by a magnetically disturbed period and the onset of equatorial spread $\mathrm{F}$ occurring at a time when the base of the $\mathrm{F}$ layer was at $320 \mathrm{~km}$; the h'F on this night showed two well marked peaks in a time interval of about $90 \mathrm{~min}$. It appears that the plasma depletions observed on this night were initiated by magnetic storm induced neutral density perturbations, which penetrated down to equatorial latitudes by large-scale planetary wave circulation.

Plasma depletions, as seen in $630 \mathrm{~nm}$, were found moving eastwards on all eight nights. Most of the plasma depletions had eastward velocities in the range of $25-125 \mathrm{~ms}^{-1}$. On one occasion (night of 29/30 March 1998), an eastward velocity as high as $182 \mathrm{~ms}^{-1}$ was also observed. On the night of 21/22 March 1998, which was a magnetically disturbed night, plasma depletions were found to be very sluggish with eastward velocities in the range of $0-25 \mathrm{~ms}^{-1}$. We feel that in the initial part of this night, the slow eastward movement of plasma depletions was due to the modification of the Fregion dynamo electric fields by direct penetration of disturbance electric fields from high-latitudes. Plasma depletions observed in the later part of the night (after 23:00 LT) could be due to dynamo field modifications either through direct electric field penetration and/or planetary wave circulation. Similar slowly moving depletions have been observed earlier by Fagundes et al. (1999).

In addition to plasma depletions, plasma enhancements or brightness patterns were also observed on many nights. The present work reports for the first time the presence of brightness patterns in the $777.4 \mathrm{~nm}$ images. It was hitherto believed 
that the brightness waves in $630 \mathrm{~nm}$ and $557.7 \mathrm{~nm}$ are a result of the MTM, which is not expected to affect the $777.4 \mathrm{~nm}$ emission. Thus, the mechanism of brightness patterns observed by us has yet to be fully understood. The brightness patterns initially appear in the northern part of the image, they grow in size and attain their peak intensity in typically about $90 \mathrm{~min}$ and in 1.5 to $2.5 \mathrm{hrs}$, these patterns encompass the entire field-of-view. These brightness patterns show slightly different behaviour in the $630 \mathrm{~nm}$ and $777.4 \mathrm{~nm}$ images. In the $630 \mathrm{~nm}$ images, the intensity of these brightness patterns shows an increase by a factor of about 1.5 from 19:30 to 21:30, whereas the $777.4 \mathrm{~nm}$ images show a decrease by a factor of 4 during the same period. Beyond 21:30, the $630 \mathrm{~nm}$ and $557.7 \mathrm{~nm}$ images show a wave type perturbation with a period of $80-90 \mathrm{~min}$. These brightness patterns are different from those reported earlier by Mendillo et al. (1997a) and Sinha and Raizada (2000), and appear to be of a new type.

Acknowledgements. The authors are thankful to the director and the staff of ISRO Telemetry Tracking \& Command Network (ISTRAC), Bangalore and Dr. G. S. D. Babu of V. B. Observatory, Kavalur for providing all necessary facilities for conducting this experiment at Kavalur. Authors are grateful to the director of the Space Physics Laboratory (SPL), Trivandrum for providing the ionograms of SHAR. This work was supported by the Physical Research Laboratory, Ahmedabad.

Topical Editor M. Lester thanks P. Fagundes and another Referee for their help in evaluating this paper.

\section{References}

Benson, R. F. and Brinton, H. C., Ionospheric plasma bubble encounters or F-region bottomside traversals, J. Geophys. Res., 88, 6243-6252, 1983.

Bittencourt, J. A., Sahai, Y., Fagundes, P. R., and Takahashi, H., Simultaneous observations of equatorial F-region plasma depletions and thermospheric winds, J. Atmos. Terr. Phys, 59 (9), 1049-1059, 1997.

Colerico, M., Mendillo, M., Nottingham, D., Baumgardner, J., Meriwether, J., Mirick, J., Reinisch, B. W., Scali, J. L., Fesen, C. G., and Biondi, M. A., Coordinated measurements of F-region dynamics related to the thermospheric midnight temperature maximum, J. Geophys. Res., 101, 26, 783-793, 1996.

Fagundes, P. R., Sahai, Y., Batista, I. S., Abdu, M. A., Bittencourt, J. A., and Takahashi, H., Vertical and zonal equatorial F-region plasma bubble velocities determined from OI $630 \mathrm{~nm}$ nightglow imaging, Adv. Space Res., 20 (6), 1297-1300, 1997.

Fagundes, P. R., Sahai, Y., Batista, I. S., Abdu, M. A., Bittencourt, J. A., and Takahashi, H., Observations of day-to-day variability in precursor signatures to equatorial F-region plasma depletions, Ann. Geophysicae, 17, 1053-1063, 1999.

Fejer B. G., Low latitude electrodynamic plasma drifts, J. Atmos. Terr. Phys, 53, 677-693, 1991.

Gonzales C. A, Kelly, M. C., Fejer, B. G., Vickrey, J. F., and Woodman, R. F., Equatorial electric fields during magnetically disturbed conditions 2 . Implications of simultaneous auroral and equatorial measurements, J. Geophys. Res., 84, 5803-5812, 1979.
Hanson, W. B. and Sanatani, S., Large Ni gradients below the equatorial F peak, J. Geophys. Res., 78, 1167-1173, 1973.

Hines, C. O., The upper atmosphere in motion, Geophys. Monogr. Ser. Vol. 18 (American Geophysical Union, Washington DC, USA), 1974.

Huang, C. S. and Kelley, M. C., Nonlinear evolution of equatorial spread-F 2. Gravity wave seeding of Rayleigh Taylor instability, J. Geophys. Res., 101, 293-302, 1996.

Jahn, J.-M., LaBelle, J., Sobral, J. H. A., Aggson, T. L., and Hanson, W. B., Detection of an equatorial spread-F bubble by ground based photometers and the San Marco 5 satellite, J. Atmos. Sol. Terr. Phys., 59, 1601-1609, 1997.

Kelley, M. C., Haerendal, G., Kappler, H., Valenzuela, A., Balsley, B. B., Carter, D. A., Ecklund, W. L., Carlson, C. W., Hausler, B., and Torbert, R., Evidence for a Rayleigh-Taylor type instability and upwelling of depleted density regions during equatorial spread-F, Geophys. Res. Lett., 3, 448-450, 1976.

Kelley, M. C., Larson, M. F., LaHoz, C., and McClure, J. P., Gravity wave initiation of equatorial spread F: A case study, J. Geophys. Res., 86, 9087-9100, 1981.

Kelley, M. C., LaBelle, J., Kudeki, E., Fejer, B. G., Basu, S., Basu, Su., Baker, K. D., Hanuise, C., Argo, P., Woodman, R. F., Swartz, W. E., Farley, D. T., and Meriwether, J., The Condor equatorial spread F-campaign: Overview and results of the large scale measurements, J. Geophys. Res., 91, 5487-5503, 1986.

McClure, J. P., Hanson, W. B., and Hoffman, J. F., Plasma depletions and irregularities in the equatorial ionosphere, J. Geophys. Res., 82, 2650-2656, 1977.

Mendillo, M. and Baumgardner, J., Airglow characteristics of equatorial plasma depletions, J. Geophys. Res., 87, 7641-7652, 1982.

Mendillo, M., Baumgardner, J., Colerico, M., and Nottingham, D., Imaging science contributions to equatorial aeronomy: initial results from the MISETA program, J. Atmos. and Solar-Terr. Phys., 59, 1587-1599, 1997a.

Mendillo, M., Baumgardner, J., Nottingham, D., Aarons, J., Renisch, B., Scali, J., and Kelley, M. C., Investigations of thermospheric-ionospheric dynamics with 6300 Åimages from the Arecibo observatory, J. Geophys. Res., 102 (A4), 7331-7343, $1997 b$.

Mukherjee, G. K., Carlo, L., and Patil, P. T., First all sky imaging observations from India, South Pacific STEP Workshop, University of Newcastle, Newcastle, Australia, 5-9 July 1993.

Prakash, S., Production of electric field perturbations by gravity wave winds in the E-region suitable for initiating equatorial spread F, J. Geophys. Res., 104 (A5), 10, 051-069, 1999.

Prolss, G. W., Perturbation of the low latitude upper atmosphere during magnetic substrom activity, J. Geophys. Res., 87, 52605266, 1982.

Prolss, G. W., Ionospheric F-region storms, Volland, H. (Ed.), Handbook of Atmospheric Electrodynamics, Vol. 2, CRC Press, Boca Raton, 195-248, 1995.

Rohrbaugh, R. P., Hanson, W. B., Tinsley, B. A., Cragin, B. L., and McClure, J. P., Images of transequatorial depletions based on field-aligned airglow observations from Haleakala in 19841986, J. Geophys. Res., 94, 6763-6770, 1989.

Sahai, Y., Aarons, J., Mendillo, M., Baumgardner, J., Bittencourt, J. A., and Takahashi, H., OI $630 \mathrm{~nm}$ imaging observations of equatorial plasma depletions at $16^{\circ}$ dip latitude, J. Atmos. Terr. Phys., 56, 1461-1475, 1994.

Sahai, Y., Fagundes, P. R., Bittencourt, J. A., and Abdu, M. A., Occurrence of large scale equatorial F-region plasma depletions during geo-magnetic disturbances, J. Atmos. Terr. Phys., 60, 
1593-1604, 1998.

Sahai, Y., Fagundes, P. R., and Bittencourt, J. A., Transequatorial Fregion ionospheric plasma bubbles: solar cycle effects, J. Atmos. Solar Terr. Phys., 62, 1377-1383, 2000.

Singh, S., Bamgboye, D. K., McClure, J. P., and Johnson, F. S., Morphology of equatorial plasma depletions, J. Geophys. Res., 102(A9), 20, 019-029, 1997a.

Singh, S., Johnson, F. S., and Power, R. A., Gravity wave seeding of equatorial plasma bubbles, J. Geophys. Res., 102(A4), 7399_ 7410, 1997b.

Sinha, H. S. S. and Raizada, S., Some new features of ionospheric plasma depletions over the Indian zone using all sky optical imaging, Earth Planets and Space, 52, 540-559, 2000.

Sinha, H. S. S., Chandra, H., Misra, R. N., and Prakash, S., Optical imaging of plasma depletions associated with equatorial spreadF, XX General Assembly, IUGG, Vienna, pp 248, 1991.

Sinha, H. S. S., Misra, R. N., Chandra, H., Raizada, S., Dutt, N., and Vyas, G. D., Multi-Wavelength optical imaging of ionospheric plasma depletions, Ind. J. Rad. and Space Phys. 25, 44-52, 1996.

Taylor, M. J., Eccles, J. V., LaBelle, J., and Sobral, J. H. A., High resolution OI $(630 \mathrm{~nm})$ image measurements of F-region depletion drifts during the Guará campaign, Geophys. Res. Lett., 24(13), 1699-1702, 1997.

Tinsley, B. A., Rohrbaugh, R. P., and Hanson, W. B., Images of transequatorial F-region depletions in 630 and $777 \mathrm{~nm}$ emissions compared with satellite measurements, J. Geophys. Res., 102(A2), 2057-2077, 1997.

Tsunoda, R. T., Time evolution and dynamics of equatorial backscatter plumes - 1. Growth phase, J. Geophys. Res., 86, 139149, 1981.

Weber, E. J., Buchau, J., Eather, R. H., and Mende, S. B., Northsouth aligned equatorial airglow depletions, J. Geophys. Res., 83, 712-716, 1978.

Woodman, R. F. and LaHoz, C., Radar observations of F-region equatorial irregularities, J. Geophys. Res., 81, 5447-5466, 1976. 